\title{
Klaus Stern, Das Staatsrecht der Bundesrepublik Deutschland (Derecho del Estado de la República Federal de Alemania (Vol. IV.2), C. H. Beck, Munich 2011, 2.234 pp.
}

Es raro que un autor en el cenit de su carrera y ya muy reconocido en el mundo entero, con una obra académica inmensa en su haber, publique, como colofón a su aportación doctrinal, un manual complementario adicional y exhaustivo de Derecho público actualizado. Este es el caso de Klaus Stern (Nüremberg, 1932) $)^{1}$, cuya ímproba y colosal obra en la literatura jurídica europea especializada quizás sólo sea equiparable en el panorama continental de hoy día, atendiendo a la continuidad en la elaboración de una sistémica teórica determinada, con los casos de Peter Häberle (Verfassungslehre als Kulturwissenschaft $)^{2}$, de Ingo von Münch (Grundgesetz-Kommentar) $)^{3}$ y, en España, de Fernández Segado (Justicia constitucional) ${ }^{4}$. Desde que saliera el volumen I de su Staatsrecht $(1977)^{5}$, sobre conceptos fundamentales y fundamentos de Derecho público y de la Constitución, Stern ha hilvanado meticulosa y progresivamente una descripción «unitaria» y cohesionada ${ }^{6}$ de las instituciones, funciones y formas de financiación del Estado (volumen II ${ }^{7}$, y de la teoría general de los derechos fundamentales en Alemania (volúmenes III.1 y III.2) ${ }^{8}$.

\footnotetext{
${ }^{1}$ Respecto a la vida y obra científica del autor, véase, OEHLING DE LOS REYES, «Aproximación a la trayectoria académica y a la obra de Klaus Stern: una vida consagrada al Derecho», en STERN, K., Jurisddción constitucional y legislador, Dykinson, Madrid, 2009, pp. 9-28.

${ }^{2}$ HÄBERLE, P., Verfassungslehre als Kulturwissenschaft, Duncker \& Humblot, Berlín, 1998. Hay traducción parcial en español a cargo de Emilio Mikunda Franco, en Teoría de la Constitución como ciencia de la cultura, Tecnos, Madrid, 2000. En la misma línea de investigación, véase, por ejemplo, «"Verfassungslehre als Kulturwissenschaft" - ein kleines Sieben-Thesen-Papier» en KOTZUR, M. / MICHAEL, L., Verfassungsvergleichung in europaund weltbürgerlicher Absicht, Duncker \& Humblot, Berlin, 2009; Erinnerungskultur im Verfassungsstaat, Duncker \& Humblot, Berlín, 2011.

${ }^{3}$ Von MÜNCH, I. / KUNIG, P. (coord..), Grundgesetz-Kommentar (Vol I-II), C. H. Beck, 6. ${ }^{\text {a }}$ Edic., Munich, 2012.

${ }^{4}$ FERNÁNDEZ SEGADO, F., La Justicia constitucional: Una visión de Derecho comparado (Vol. I, II y III), Dykinson, Madrid, 2008.

${ }^{5}$ STERN, K., Das Staatsrecht der Bundesrepublik Deutschland: Grundbegriffe und Grundlagen des Staatsrecht, Strukturprinzipien der Verfassung, C. H. Beck, Munich, 1977. Hay traducción parcial de Javier Pérez Royo y Pedro Cruz Villalón, bajo el título Derecho del Estado de la República Federal Alemana, CEPC, Madrid, 1987.

${ }^{6}$ Compárese, GONZÁLEZ ENCINAR, J. J., «Sobre el sistema de los derechos fundamentales. Con motivo del libro de Klaus Stern Das Staatsrecht der Bundesrepublik Deutschland», en Revista española de Derecho Constitucional, año 15, n. ${ }^{\circ}$ 25, CEPC, Madrid, 1995, pp. 369.

${ }^{7}$ STERN, K., Das Staatsrecht der Bundesrepublik Deutschland: Staatsorgane, Staatsfunktionen, Finanz und Haushaltsverfassung, Notstandsverfassung, C. H. Beck, Munich, 1980.

${ }^{8}$ STERN, K. / SACHS. M., Das Staatsrecht der Bundesrepublik Deutschland: Allgemeine Lehren der Grundrechte. Grundlagen und Geschichte, nationaler und internationaler
} 
El antepenúltimo número de la obra-Fundamentos históricos del Derecho público (2000) ${ }^{9}$ - es una referencia a la Historia cómo base de la Teoría de la Constitución y del Estado en Alemania, prestando especial atención al hecho inevitable de la separación RFA y RDA durante la Guerra Fría y al proceso subsiguiente de reunificación ${ }^{10}$. Finalmente, la penúltima entrega (IV.1 $)^{11}$, previa a la aquí comentada, no sólo fue una relación del estado de situación actual de garantía de los derechos individuales en Alemania, sino que incluyó un estudio profuso de casos prácticos de colisión de derechos e intereses estatales. Este trabajo, en sí, demuestra la plasticidad o la dimensión expansiva de los derechos constitucionales y cómo y en qué forma, en la actualidad, en el fondo, toda disputa o litigio tiene realmente un estro inseparable de tipo jurídico-constitucional ${ }^{12}$.

La culminación de este último volumen lo ha realizado en comandita con Michael Sachs y Johannes Dietlein, dos de sus más fieles colaboradores, y con la satisfacción de quien cumple un sueño de toda una vida, más si tenemos en cuenta que poco antes hizo otra aportación con motivo de los sesenta años de la Ley Fundamental ${ }^{13}$. «Con la terminación de este trabajo doy cumplida realización a la promesa que ya hiciera en el prólogo del primer volumen en 1977, a saber, la de realizar un manual sistemático completo de Derecho público alemán», recuerda ahora en la introducción el autor. El nuevo tomo ofrece, junto con la primera parte del volumen IV, una panorámica global de todos los derechos fundamentales de la Ley Fundamental. El trabajo hace re-

Grundrechtkonstitutionalismus, juristische Bedeutung der Grundrechte, Grundrechtsberechtigte und Grundrechtsverpflichtete, Vol. III.1 C. H. Beck, Munich, 1983; Das Staatsrecht der Bundesrepublik Deutschland: Allgemeine Lehren der Grundrechte.Grundrechtstatbestand, Grundrechtsbeeinträchtigungen und Grundrechtsbegrenzungen, Grundrechtsverluste und grundpflichten, Schutz der Grundrechte, Grundrechtskonkurrenzen, Vol. III.2 C. H. Beck, Munich, 1994.

${ }^{9}$ STERN, K., Das Staatsrecht der Bundesrepublik Deutschland: Allgemeine Lehren der Grundrechte: Die geschichtlichen Grundlagen des deutschen Staatsrecht, die Verfassungsentwicklung vom Alten Deutschen Reich zur Wiedervereinigten Bundesrepublick, Beck, Munich, 2000.

${ }^{10}$ Véase, así, FROMME, F. K., «Enstation Staatsrecht Geschichtliche Grundlagen: Klaus Sterns Lebenswerk steht vor der Vollendung», recensión al Das Staatsrecht der Bundesrepublik Deutschland, Vol. V, en Frankfurter Allgemeine, edición de 18 de abril de 2001, n. ${ }^{\circ} 90$, p. 9.

${ }^{11}$ STERN, K. / SACHS, M. / DIETLEIN, J., Das Staatsrecht der Bundesrepublik Deutschland: Die einzelnen Grundrechte. Der schutz und die freiheitliche Entfaltung des Individuums, Beck, Munich, 2006.

${ }^{12}$ En este sentido, véase, MÜLLER, R., «Bisweilen undurchsichtig: Ein monumentales Werk über die einzelnen Grundrechte», recensión al Das Staatsrecht der Bundesrepublik Deutschland, Vol. IV.1, en Frankfurter Allgemeine, edición de 6 de marzo de 2007, n. ${ }^{\circ}$ 54, pp. 7 y 8.

${ }_{13}$ STERN, K. (coord..), 60 Jahre Grundgesetz. Das Grundgesetz für die Bundesrepublik Deutschland im Europäischen Verfassungsverbund, C. H. Beck, Munich, 2010. 
ferencia a en torno veinticinco artículos que tienen identidad propia y alto potencial significativo, pero que han adquirido, dado el orden valorativo actual, una estructura normativa que reviste la totalidad del ordenamiento jurídico y ha dado lugar a un nivel de garantías en Alemania hasta ahora nunca conocido, apuntaba Stern en el discurso de presentación de la obra en el Hotel Hyatt de Colonia, el día 10 de diciembre de 2010. La obra incluye, entre otras cosas, estudios sobre la libertad de actuación política, la libertad religiosa, el derecho a la educación y el principio de igualdad, pero también un capítulo dedicado a la dimensión jurídico-fundamental de la tutela judicial y la responsabilidad del Estado, en relación con los conceptos de restitución e indemnización, dado que, como es sabido, a pesar de la vinculación de todo el poder del Estado a los derechos fundamentales, las lesiones a éstos y las extralimitaciones de la máquina estatal son factibles y, en estos casos, deben de extremarse las precauciones y, en su caso, asegurarse vías de sanción y reparación ${ }^{14}$.

Un trabajo del porte y calidad del Staatsrecht der Bundesrepublik Deutschland IV.2 ofrece-evidencia de Perogrullo-innumerables aspectos bajo los cuales se puede valorar su importancia. Tenemos el análisis personal de Stern de los derechos culturales y su interpretación, en la línea de Smend ${ }^{15}$ y Häberle, de la «interconexión íntima entre derechos fundamentales y cultura», es decir, su comprensión del derecho a la educación, de la escolarización, de la libertad científica o artística y la colaboración de los mass media como parte integrante de la «Constitución cultural» y «base sobre la que se construye una sociedad». Aquí también se podría destacar el estudio jurídico de la cultura política y de las instituciones u organizaciones -aparte de las escuelas, academias y las universidades- que materializan los derechos culturales, como, por ejemplo, los institutos nacionales y los medios de representación de la cultura y la realidad actual alemana (Goethe-Institut, festividades nacionales, el himno naciona $1^{16}$ o la responsabilidad por el Holocausto). Tenemos, por obra de Sachs, la referencia a la dicotomía principio de igualdad-no discriminación (artículo 3 de la Ley Fundamental), su diferenciación y taxonomía constitucional y el análisis sobre la difícil aplicabilidad de estos conceptos a las personas jurídicas o entidades de Derecho público. Tenemos la relación de Dietlein respecto a la teoría de conformación de la voluntad popular y su articulación a través de los derechos de participación política, las elecciones y el proceso de formación de opinión en la socie-

${ }^{14}$ El discurso pronunciado por el profesor Klaus STERN en la presentación del Das Staatsrecht der Bundesrepublik Deutschland, Vol. IV.2, está disponible en alemán en formato digital en la página de Internet de la editorial C. H. Beck, en http://rsw.beck.de/CMS/?toc=Presse. $57 \&$ docid=312679.

${ }^{15}$ SMEND, R., Verfassung und Verfassungsrecht, München, Lepizig, 1928.

${ }^{16}$ Sobre ello, véase, por ejemplo, HÄBERLE, P., El himno nacional como elemento de identidad cultural del Estado constitucional, Dykinson, Madrid, 2012. Traducción de Alberto Oehling de los Reyes. 
dad pluralista. Ahora bien, la multiplicidad de aspectos sobre los cuales se puede valorar la obra se aprecian en ningún otro tema con tanta expresividad como en el análisis de Stern de la cuestión de la libertad religiosa. No cabe duda que la inmigración extraeuropea y la llegada de nuevas sensibilidades religiosas inició un periodo muy fecundo al respecto en la doctrina científica, no sólo en Alemania. Más en este trabajo se va un poco más allá pues se hace referencia complementaria de forma perspicua a situaciones muy actuales de trasfondo social y político como son, entre otros, el tema de la legalidad de las sectas y los casos problemáticos derivados de la no siempre fácil conjugación de diversas interpretaciones del Islam con la teoría occidental de los derechos fundamentales. La novedad del autor ha consistido en analizar además con encomio la cobertura jurídico-constitucional de determinadas formas de exteriorización de la fe religiosa, tales como el kippa, el turbante, la chilaba o la barba, pero también otras más enfáticas como el pañuelo islámico o el vestido Bhagwan.

El número IV.2, desde nuestro punto de vista, es además, aunque complementario, el más desarrollado de la colección. El autor, sin dejar de hacer referencias teóricas al ius politicum, buscando la interrelación con el Derecho natural, civil y de gentes, y sin dejar de lado los conceptos de la Historia política, la Filosofía política y la Sociología - materias conexas al Derecho constitucional-, proyecta su propuesta metodológica por la integración en el manual de comentarios extensos de interdependencias de Alemania en el marco europeo, de la jurisprudencia de órganos supranacionales y de Derecho comparado. En este contexto, el mayor logro del manual consiste en ofrecer un corpus teórico coherente, in extenso, para mí convincente, de interconexión directa entre los institutos y conceptos jurídico-constitucionales vigentes y la Historia de las instituciones y como consecuencia última de la comprensión del hombre de acuerdo a la tradición occidental, la filosofía de la antigüedad, el Cristianismo, el Derecho natural y el pensamiento ilustrado» ${ }^{17}$. Empero, en otros aspectos, especialmente en el análisis de puntos que hacen referencia a cuestiones de rabiosa actualidad, por ejemplo, el tratamiento jurídico de las formas de expresión de la religión mahometana o la aplicación de nuevas tecnologías a efectos de implementación de derechos individuales -como podemos ver en esta recensión siquiera de forma nimia-, utiliza con exactitud y amplia perspectiva las premisas metodológicas de dogmática jurídica de los concretos preceptos constitucionales y de su desarrollo legal y jurisprudencial y de Derecho comparado.

Estructuralmente, como se ha dicho, este volumen forma parte de la serie «Los derechos fundamentales individuales» (Die einzelnen Grundrechte),

${ }^{17}$ Sobre ello, véase también, por ejemplo, STERN, K., «Menschenwürde als Wurzel der Menschen- und Grundrechte», en Norbert ACHTERBERG (coord..), Recht und Staat im sozialen Wandel. Festschrift Hans Ulrich Scupin zum 80. Geburtstag, Duncker \& Humblot, Berlín, 1983, pp. 627-640. 
concebida en seis capítulos: por un lado, el tomo IV.1 integra los capítulos 1 y 2 , referidos a la existencia del sujeto, el desarrollo de la personalidad, la posición jurídica del individuo y los derechos de libertad; por otro lado, el tomo IV.2 está dividido en cuatro partes, tratando gradualmente las libertades políticas, el derecho a la cultura (escolarización, educación, arte y ciencia), la libertad religiosa e ideológica (religión e Iglesia), el principio de igualdad y la tutela judicial.

La primera subparte de esas cuatro partes del tomo IV.2 que hemos citado correspondería al capítulo 3, a través del cual se analizan los derechos de la persona en cuanto miembro de la sociedad política, y con ello, como materia aparte, el régimen jurídico práctico de participación y el derecho de sufragio. Esto significa que aquí se hace referencia, entre otras cosas, a las permisas del Estado democrático, la concepción plural de la sociedad, la promoción de las inquietudes políticas del ciudadano, el papel de los partidos «como intermediarios entre el pueblo y los órganos estatales», la influencia de los medios como «cuarto poder», la significación de Internet como medio de intervención en el proceso de formación de la voluntad popular y las garantías que aseguran la pureza del proceso electivo. Igualmente, se analizan derechos conexos como la prohibición de discriminación por motivos políticos, la libertad de expresión, el derecho de reunión, el derecho a la confidencialidad o la integridad de los sistemas técnicos de almacenamiento de datos personales y, finalmente, la importancia de la libertad de prensa y la proscripción de la censura. La segunda parte (capítulo 4), dedicada al derecho a la educación y la libertad religiosa e ideológica, es de una importancia si cabe mayor y representa toda una teoría de fundamentación de la idea de la Constitución cultural. Aquí se estudian el concepto griego de paideia, la articulación de la educación en la antigua Roma a través de la figura del pater familias y la evolución de la instrucción pública en Alemania desde la Edad Media y la Reforma hasta la actualidad. A ello sigue la comprensión del derecho a la educación en la Ley Fundamental, que incluye, entre otras cosas, referencias a cuestiones peculiares como la regulación de los Länder en materia de educación y la coordinación de éstos con el Ministerio de educación y ciencia para el planeamiento de líneas uniformes de actuación. Las páginas de esta parte integran dificultades específicas que amenizan la lectura del capítulo, como, por ejemplo, la explicación del problema de la enseñanza de religión islámica en los colegios e institutos alemanes y la cuestión de la ropa deportiva de las escolares islamitas en clase de gimnasia. Se cierra esta segunda parte con el examen de la libertad artística y científica, en que de nuevo sale a relucir la cuestión de la libertad religiosa. El estudio comparado de estos derechos en los Estados de la Unión Europea, EE.UU. y en el nivel internacional es completísimo, brillante en su desarrollo y lleno de erudición. La tercera (capítulo 5) es una exhaustiva exposición sobre el principio de igualdad y no discriminación en Alemania. Esta parte incluye, entre otras cosas, referencias al nivel de implementación de la igualdad de derechos hombre-mujer en el 
marco del ordenamiento jurídico, es decir, que explica el grado de progresión de los derechos de la mujer en Alemania en ámbitos concretos como, por ejemplo, el derecho de familia, los derechos sociales, los derechos funcionariales y el derecho al trabajo. Asimismo, se analiza con profundidad y amplia perspectiva la integración de la mujer en el Servicio Militar. La ultima parte, en fin (capítulo 6), comprende la relación de las vías de tutela judicial y garantías jurídicas específicas frente a lesiones de los derechos individuales por el poder público. Esto supone que aquí se analizan detalladamente la teoría de los derechos fundamentales como derechos subjetivos, el derecho de libre acceso al proceso, especialmente el derecho de defensa sin que se pueda producir indefensión, el derecho de acceso a los recursos legales y las garantías constitucionales del proceso, e igualmente la protección del perjudicado, el derecho de responsabilidad civil y el derecho de indemnización.

En definitiva, de auténtico acontecimiento científico y cultural hay que valorar la publicación del último número del Staatsrecht editado por la mítica editorial alemana C. H. Beck. Con este tomo, al que pronto se unirá, cerrando el círculo, la publicación de las contribuciones realizadas con motivo de la presentación del libro en Colonia el día 10 de diciembre de $2010^{18}$, la Ciencia del Derecho público europeo está de enhorabuena. Pocos manuales de Derecho constitucional revelan una sistemática y perfección metódica como esta colección de Stern. Impresionante relación teórica y práctica de Derecho constitucional y Derecho político, donde se hace uso de una metodología precisa y con una habilidad no siempre habitual en los manuales de sistematización especializados. La obra se presenta además con un lujo y una prolijidad exquisita, aparte del papel cebolla típico de esta clase de trabajos, incluye los índices de los seis volúmenes anteriores (I-II, III.1-III.2, IV.1 y V), una tabla de abreviaturas exhaustiva y un índice de materias completo elaborado por la Dra. Helga Stern, esposa y compañera de fatigas del profesor Stern. En suma: El nuevo número del Staatsrecht der Bundesrepublik Deutschland es mucho más que una obra de un autor en el culmen de su carrera científica y mucho más que un manual de Derecho constitucional alemán. Ha abierto un nuevo método de estudio del Derecho público, difícilmente igualable, cual es la elaboración de una sistemática total de Derecho constitucional consolidado con las interrelaciones e interdependencias del marco europeo, la cultura común europea y las instancias del orden supranacional. Ha dado luz a muchos problemas típicos de Derecho político y constitucional y facilita nuevas vías para la investigación de problemas sociales, políticos, religiosos y económicos de actualidad. Es un libro colosal, in aeternun. Es una obra magna que puede contribuir - ese es el deseo de Stern- «para preservar el Estado de Derecho, la libertad personal, la democracia y la estabilidad política», tanto en Alemania

${ }^{18}$ STERN, K. (coord..), Stern (Hrsg.), Präsentationsfeier zur Vollendung des Staatsrechts der Bundesrepublik Deutschland (en prensa). 
como en Europa. Toda biblioteca de una facultad de Derecho, a partir de este momento, se puede considerar incompleta si carece de este indispensable volumen.

Alberto Oehling de los Reyes Universidad de las Islas Baleares 